\title{
Finding the Optimal Condition of Exterior Spray Coating for Cookware Products
}

\author{
Yaowarak Wongyai $^{1, a}$, Suksan Prombanpong ${ }^{1, b}$ \\ 1 Department of Production Engineering, Faculty of Engineering, King Mongkut's University of Technology Thonburi (KMUTT), Bangkok,
} 10140, Thailand

\begin{abstract}
This research aims at studying the relationship of factors used in the process of spray coating in cookware industry. This research is divided into two parts. One is studied using an experimental design process, and the other is the geometric modeling for the process of exterior spray coating. This experiment is conducted to determine the appropriate parameters with an aim to use the least amount of coating material and the standard dry film thickness. The important factors of study are consisted of the height of spray gun, angle, spray pressure, spray time, and nozzle size. From the analysis of the experiment, it can be concluded that $23 \mathrm{~cm}$ of height, 95 degrees of gun angle, 5.4 bar of air pressure 1.95 seconds of spray time, 295 degrees of nozzle size is proposed. As a result, it can decrease the consumption around $2.82 \mathrm{~g}$ per piece.
\end{abstract}

\section{Introduction}

In cookware industry, apart from the standard size and shape of the product, the coating apprearance is another important factor to maintain the quality of the product's surface as well. The coating prevents the corrosion, moisture in the material, and in terms of aesthetic. The coating also helps to decorate the product's surface in the final process. These will affect the quality of the product. Due to highly competitive and rising cost of production such as raw material and labor cost, it results in reducing cost of production. However, this satisfies the customers' demands and the product quality

According to the literatures, it is found that one of the quality problems is related to dry film thickness (DFT) which does not match with the specification. This problem is mainly due to setting of a spray gun. A number of studies are undertaken in the analyses of spraying path, spray overlap, spray gun orientations and spray flow rate $[1,2,3]$. At the beginning of the production, a technician attempts to setup the spray gun so that the coating thickness is obtained because the appropriate condition of the spray gun will increase quality of the product $[4,5,6]$. However, a determination of an optimal spray condition is not easy to find. Few literature has been conducted to determine the spray condition i.e. spray time, nozzle size, and air pressure to satisfy DFT with minimum material conumption $[7,8]$. Nevertheless, other factors such as spray position, gun angle has not yet been studied to see the effect of these mentioned parameters to DFT and material consumption. Therefore, this paper will investigate mentioned parameters to the DFT and material consumption for better understanding and result.

\section{Design of Experiment}

The color used for coating was enamel color, which was caused by the body color was mixed with varnish. Enamel color would be dry in the air or by heating from the oven. The color of this would have smooth surface; including strong resistance to have corrosion and some scratches after the color had dried. The amount of the required dry film thickness was $55-65 \mathrm{pm}$. There were 5 parameters used in this study; for example, Height, Gun Angle, Air Pressure, Spray Time, and Nozzle Size. The experiment was repeated twice for a total of 64 experimental trials to determine the appropriate parameter of spray coating process. The researcher used instrument for the experimental design in the form of $2 \mathrm{k}$ Factorial Design as shown in Table 1.

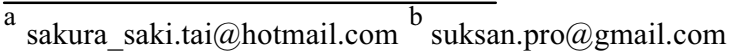


Table 1 The level of factors used for experiment

\begin{tabular}{lcc}
\hline \multicolumn{1}{c}{ Factors } & Min & Max \\
\hline Height (cm) & 23 & 24 \\
Gun Angle (degree) & 90 & 95 \\
Air pressure (bar) & 5 & 5.4 \\
Spray time (s) & 195 & 2.00 \\
Nozzle size (degree) & 295 & 300 \\
\hline
\end{tabular}

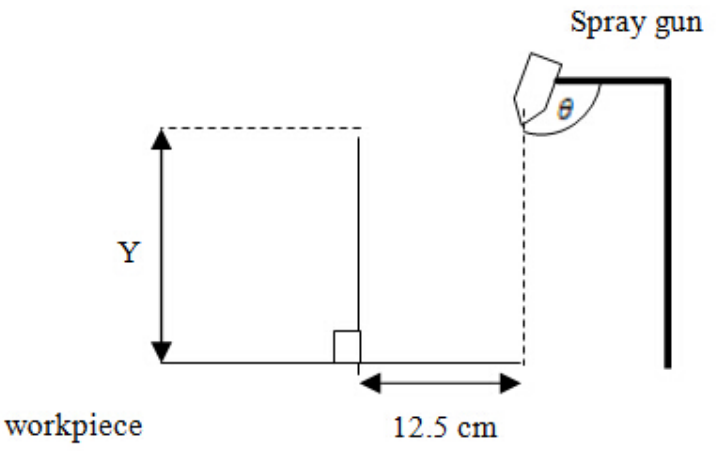

Figure 1. Positions and angle of spray gun respecting to the workpiece surface

\section{Results and Discussions}

Statistical analysis

The experimental results analysis was from evaluating data with computer program to analyze the results related to the ability in describing the variation of factors; and the factors which effect on the responded variable. The researcher used the computer program for analyzing the results of thickness as shown in Table 2; and the amount of colors as shown in Table 3 which was described the variation of the factors in the experiment; and the factors which effect on the responded variable by using the Pvalue to accept or reject the hypothesis with the significance level at 0.05 .

Table 2 The statistic analysis of dry film thickness (DFT)

\begin{tabular}{ll}
\hline \multicolumn{1}{c}{ Term } & P-value \\
\hline Height & 0.240 \\
Gun Angle & 0.313 \\
Air Pressure & 0.073 \\
Spray Time & 0.000 \\
Nozzle size & 0.000 \\
Gun Angle*Air Pressure & 0.042 \\
Spray Time*Nozzle size & 0.000 \\
Height *Gun Angle*Spray Time & 0.029 \\
Height *Air Pressure*Spray Time & 0.028 \\
Gun Angle*Air Pressure*Spray Time & 0.008 \\
S $=1.08152 \quad$ PRESS = 90.3973 & \\
R-Sq $=93.26 \% \quad$ R-Sq(pred) $=90.17 \% \quad$ R-Sq $(\operatorname{adj})=91.99 \%$ & \\
\hline
\end{tabular}

Table 3 The statistic analysis of Material consumption

\begin{tabular}{ll}
\hline Term & P-value \\
\hline Air Pressure & 0.035 \\
Spray Time & 0.000 \\
Nozzle size & 0.000 \\
Spray Time*Nozzle size & 0.000 \\
$\mathrm{~S}=0.784509 \quad$ PRESS $=42.727$ & \\
$\mathrm{R}-\mathrm{Sq}=96.99 \% \quad \mathrm{R}-\mathrm{Sq}($ pred $)=96.46 \% \quad \mathrm{R}-\mathrm{Sq}(\mathrm{adj})=96.79 \%$ & \\
\hline
\end{tabular}

Effect of spray conditions

The Fig. 2 This graph showed the co- responding influence of factors that affected on the dry film thickness. Results can be analyzed as follows:

- Gun Angle and Air Pressure that affected on the dry film thickness. If Gun Angle and Air Pressure at a high level, resulting in a coating thickness increases. Because the Gun Angle used 95 degree with the work piece makes colors come out with an even wider dispersion than the Air Pressure in the high level. The amount of color on the work piece increases.

- Spray Time and Nozzle size that affected on the dry film thickness. Due to time increased use and when to adjustment Nozzle size a larger color come out there will be plenty more to come in the colors on the surface increases.

- Height, Gun Angle and Spray Time that affected on the dry film thickness. The distance of the gun, Gun Angle and Spray time is high. Gun angle to the work 
piece within the color spreads out on the surface of the work piece and the time it takes to spray more, the thickness is increased.

- Height, Air Pressure and Spray Time that affected on the dry film thickness. The distance between the gun and the air pressure is high. The time it takes to spray more the colors on the surface with ever-increasing amount.
- Gun Angle, Air Pressure and Spray Time that affected on the dry film thickness. The Gun Angle with the work piece. Low air pressure in the amount of paint that comes out is not dispersed and not hardened before sticking on the work piece. And when added to spray for longer periods make the colors come out more and thickness increase.

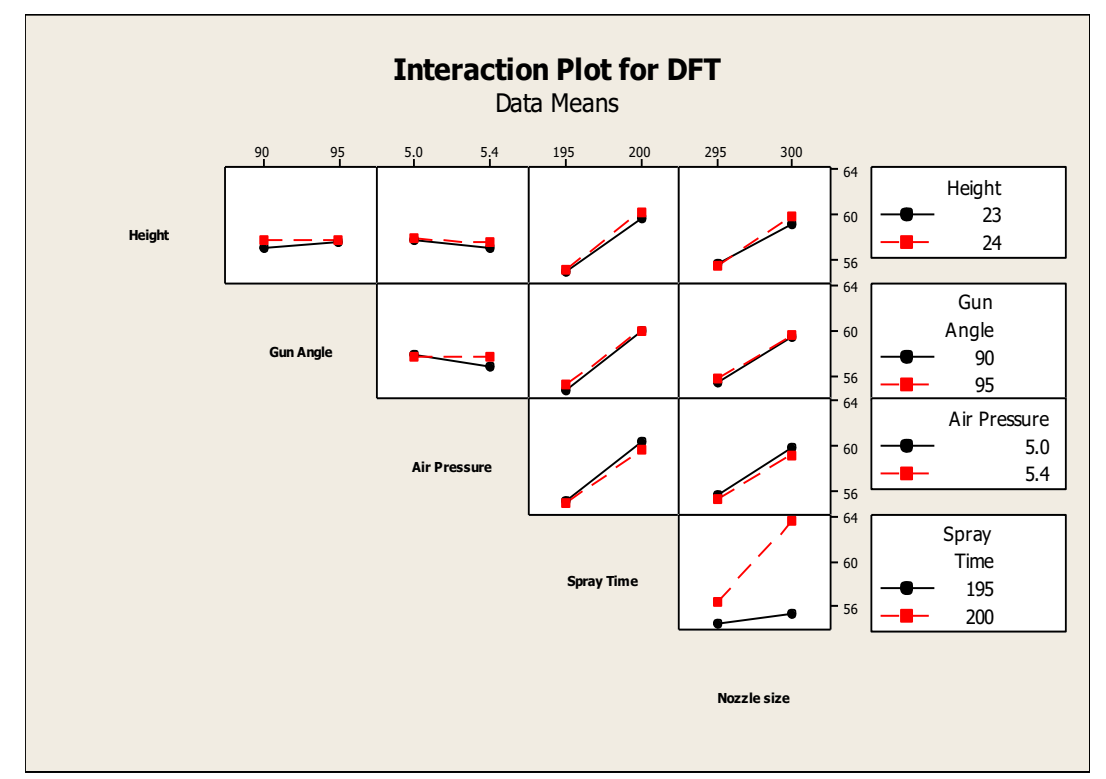

Figure 2. The graph shown the co- responding influence of factors affected on the dry film thickness

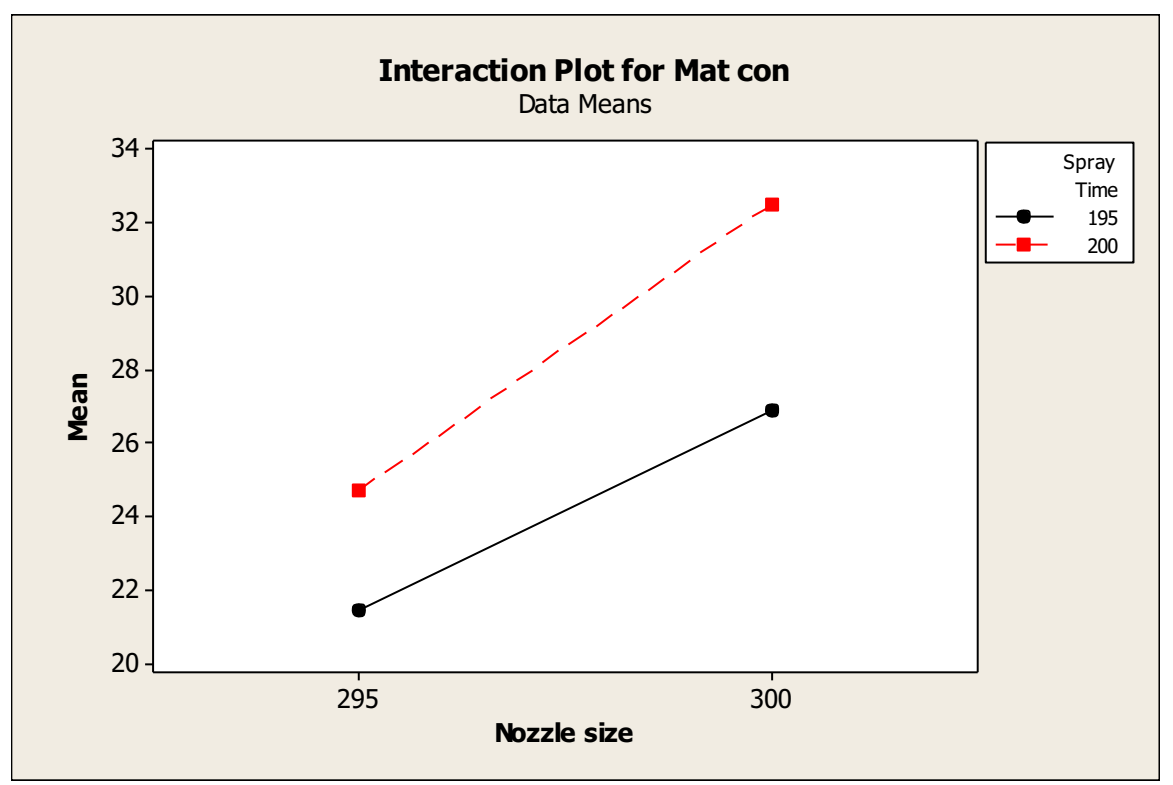

Figure 3. The graph shown the co- responding influence of factors affected on the volume of dry film thickness

This graph showed the co- responding influence of factors that affected on the dry film thickness. It can be seen that the high Spray Time and the high Nozzle size would increase the amount of color. In contrast, if the time the low Spray Time and the low Nozzle size would decrease the amount of spray coating as shown in Fig.2.

\section{Parameters Optimization}

When setting of each parameter with the appropriate value, it consisted of $23 \mathrm{~cm}$ of Height, 95 degree of Gun Angle, 5.4 bar of Air Pressure, 1.95 seconds of Spray Time, and 295 degree of Nozzle size. Moreover, ANOVA was able to create Regression model for forcasting the value of dry film thickness (DFT) as shown in equation (1) and he material consumption (MC) as shown in equation (2) 

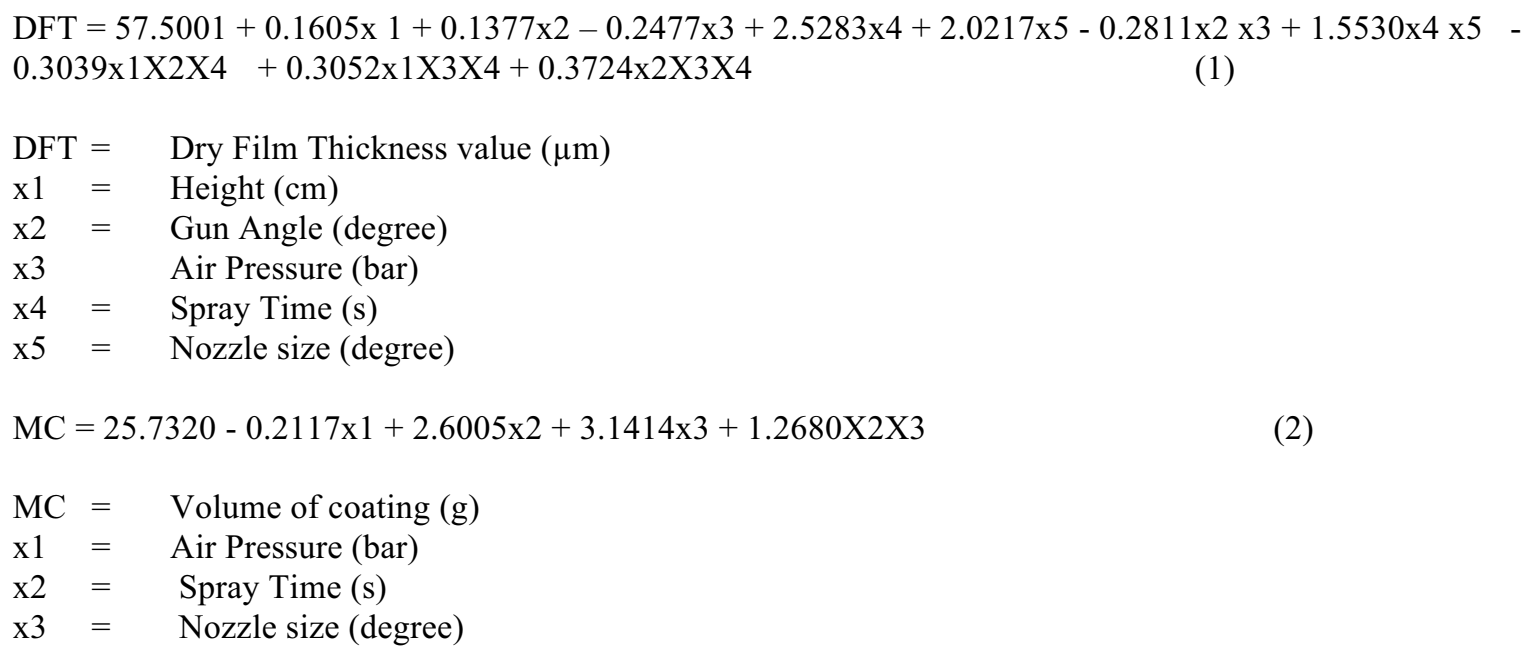

\section{Summary}

According to the results of spray coating process in kitchenware industry, when it was followed to do the process of experimental design and result analysis by computer program with a significance level at $0.05(\alpha=$ $0.05)$. It was indicated that there were interaction factors that affected the thickness of a color consisted of Gun angle and Air Pressure, Spray time and Nozzle size, Height Gun angle and Spray time, Height Air pressure and Spray time, Gun angle Air pressure and Spray time which affected on the thickness of color. The factors that affected on the Material Consumption was Spray Time and Nozzle size with the appropriate values of $23 \mathrm{~cm}$ of Height, 95 degrees of Gun angle, 5.4 bar of Air Pressure, 1.95 seconds of Spray time, and 295 degrees of Nozzle size. From this, it could decrease the material consumption about $2.82 \mathrm{~g}$ per work piece.

\section{References}

1. Kout A, Muller H. Parameter optimization for spray coating. Proc. of The Advances in Engineering Software Vol.40(2009), p.1078-1086.

2. From PJ, Gunnar J, Gravdahl JT. Optimal paint gun orientation in spray paint applications-exprimental results. Proc. IEEE Transaction on Automation Science and Engineering (2011) p. 438-442.

3. Wang Z, Liu C, Cheng L, Fan X. Optimization of Spraying Path Overlap Rate Based on MATLAB.
Proc. IEEE Consumer Eletronics, Communications and Networks(CECNet) (2012), p. 2731-2734.

4. Hong, S., Wu, Y., Wang, B., Zheng, Y., Gao, W., Li, G.: High-Velocity Oxygen-Fuel Spray Parameter Optimization of Nanostructured WC-10Co-4Cr Coatings and Sliding wear Behavior of the Optimized Coating. Proceeding of Materials and Design. Vol.55 (2014), p. 286-291

5. Kang,J.J., Xu, B.S.,Wang, H.D. Wang, C.B.: Influence of Spraying Parameters on the Microstructure and Properties of Plasma-Sprayed A12O3/40\% TiO2 Coating. Proceedings of Heat Treatment and Surface Engineering. Vol.50 (2013), p. 169-176

6. Song, E.P., Ahn, J., Lee, S., Kim, N.J.: Effects of Critical Plasma Spray Parameter and Spray Distance on Wear Resistance of A12O3-8 wt.\%TiO2 Coatings Plasma-Sprayed with Nanopowders. Proceeding of Surface and Coatings Technology. Vol.202 (2008), p.3625-3632

7. Luangkularb, S., Prombanpong, S., V. Tangwarodomnukun: Material Consumption and Dry Film Thickness in Spray Coating Process. Proceedings of the 47th CIRP Conference on Manufacturing Systems. Vol.17 (2014), p.789-794

8. Winnicki, M., Małachowska, A., Ambroziak, A.: Taguchi Optimization of the Thickness of a Coating Deposited by LPCS. Archives of Civil and Mechanical Engineering. Vol.14 (2014), p. 561-568 